\title{
Re-Evaluating Biologic Pharmacotherapies That Target the Host Response during Sepsis
}

\author{
Kristopher M. Tuttle ${ }^{1, \dagger}$, Matthew D. McDonald ${ }^{1,+}$ and Ethan J. Anderson ${ }^{1,2, *}$ \\ 1 Department of Pharmaceutical Sciences \& Experimental Therapeutics, College of Pharmacy; University of \\ Iowa, Iowa City, IA 52242, USA; kris-tuttle@uiowa.edu (K.M.T.); matthew-mcdonald@uiowa.edu (M.D.M.) \\ 2 Fraternal Order of Eagles Diabetes Research Center, University of Iowa, Iowa City, IA 52242, USA \\ * Correspondence: ethan-anderson@uiowa.edu \\ + These authors contribute equally to this work.
}

Received: 10 October 2019; Accepted: 26 November 2019; Published: 30 November 2019

\begin{abstract}
Multiple organ dysfunction syndrome (MODS) caused by the systemic inflammatory response during sepsis is responsible for millions of deaths worldwide each year, and despite broad consensus concerning its pathophysiology, no specific or effective therapies exist. Recent efforts to treat and/or prevent MODS have included a variety of biologics, recombinant proteins targeting various components of the host response to the infection (e.g., inflammation, coagulation, etc.) Improvements in molecular biology and pharmaceutical engineering have enabled a wide range of utility for biologics to target various aspects of the systemic inflammatory response. The majority of clinical trials to date have failed to show clinical benefit, but some have demonstrated promising results in certain patient populations. In this review we summarize the underlying rationale and outcome of major clinical trials where biologics have been tested as a pharmacotherapy for MODS in sepsis. A brief description of the study design and overall outcome for each of the major trials are presented. Emphasis is placed on discussing targets and/or trials where promising results were observed. Post hoc analyses of trials where therapy demonstrated harm or additional risk to certain patient subgroups are highlighted, and details are provided about specific trials where more stringent inclusion/exclusion criteria are warranted.
\end{abstract}

Keywords: sepsis; pharmacology; biologics; multiple organ dysfunction syndrome; inflammation; coagulation

\section{Introduction}

Sepsis has recently been defined clinically as "a life-threatening organ dysfunction caused by a dysregulated host response to infection" [1]. While standard of care generally focuses on antimicrobial and supportive therapies [2], the effects of acute inflammation in the host (i.e., the patient) must also be addressed. The acute inflammatory component of sepsis, often referred to as systemic inflammatory response syndrome (SIRS), involves the coordinated release of cyto/chemokines, arachidonic acid metabolites, complement, and many other proteins, typically from liver and immune cells. A similar response occurs in many types of injuries, including traumas and burns [3]. Currently, sepsis accounts for $>750,000$ intensive care unit admissions annually and has been reported to be rising [4]. Despite major advances in emergency medicine in recent decades, mortality rates with sepsis still remain high, reaching greater than $30 \%$ if patients develop multiple organ dysfunction syndrome (MODS) $[5,6]$. Thus, there is an urgent need to identify new drug targets and develop new pharmacotherapies directed at those targets, which can halt the development of MODS.

Recombinant proteins (i.e., 'biologics') have become a prominent class of medications to combat both rare and common conditions. They represent a new era of promising medications, and unlike 
small molecules, biologics can be engineered to serve as decoys, mimics, or direct inhibitors of many types of proteins, including cyto/chemokines, growth factors, immunoglobulins, and enzymes. Recent efforts to use biologics in conjunction with standard-of-care approaches have seen mixed results, but several have shown promise. Major unique challenges exist with sepsis trials, specifically with respect to identifying who to treat and when to treat them (i.e., the therapeutic 'window'), the highly variable source of the infection, and the presence of confounding co-morbidities in many patients [2].

This review summarizes the underlying rationale and outcome of major clinical trials where biologics were tested as a pharmacotherapy for MODS in sepsis. Trials discussed are grouped by target (Figure 1), and a brief description of the study design and overall outcome are presented for each of the major trials. Targets and/or trials that show promise are emphasized in greater detail than those that clearly failed to show favorable effects. A summary of these trials and their outcomes, along with the current status of each biologic class that is discussed, is provided in Table 1.

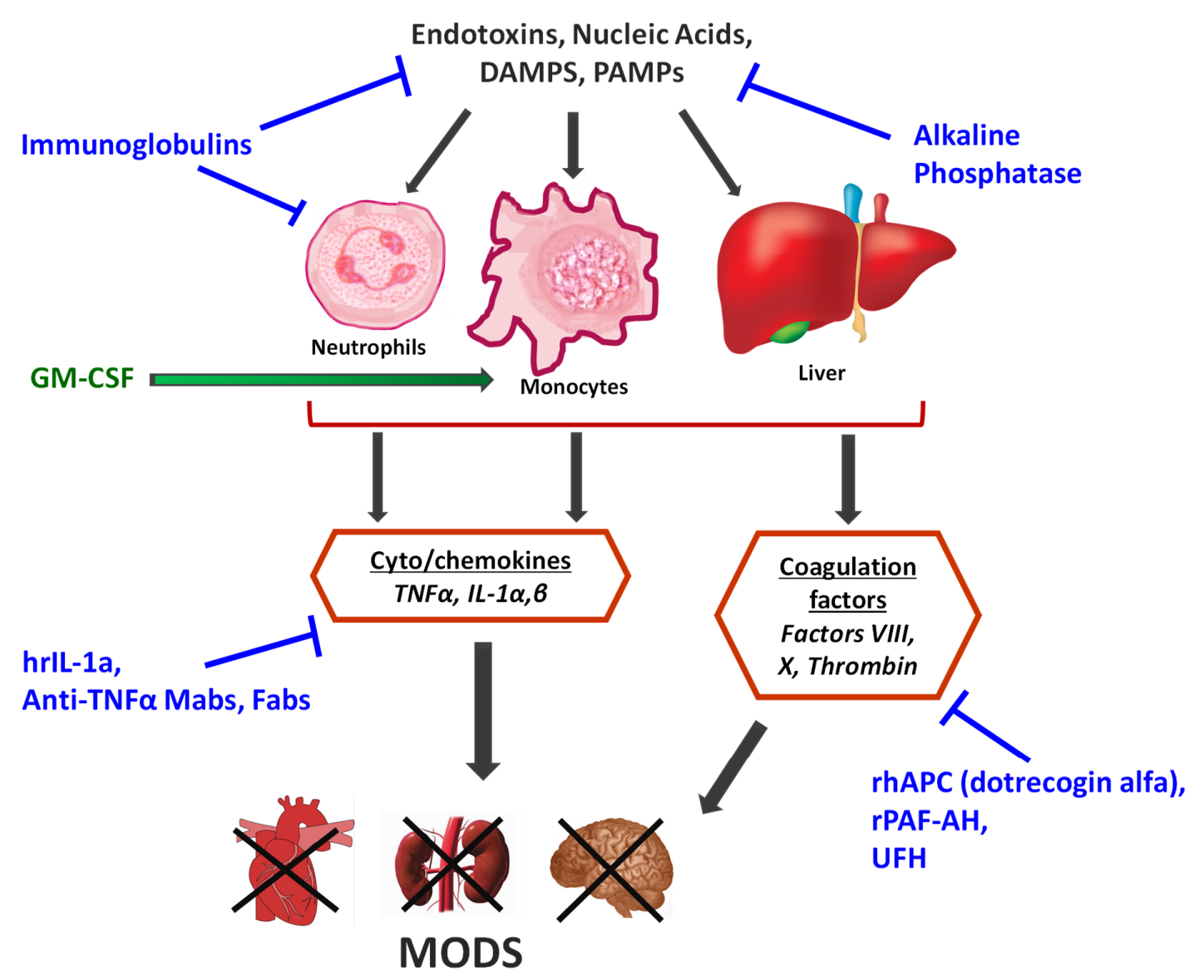

Figure 1. Major sources of inflammation and coagulation in the host response to sepsis that have been targeted in the past 20 years with biologics. Therapies directed at blocking a certain response are shown in blue text, and those that enhance a specific response are in green text.

\section{Targeting Cyto/Chemokines}

Inflammation in sepsis begins when the host's innate immune response becomes activated, primarily via toll-like receptors (TLRs). TLRs activate a plethora of signaling cascades, which ultimately results in the generation of numerous inflammatory cytokines and chemokines, the most-characterized of which include tumor necrosis factor alpha (TNF $\alpha$ ), interleukins (ILs), and others [7]. Upon activation, TLRs (among others) induce the rapid synthesis and secretion of IL- $1 \beta$ which acts as a positive feedback signal to re-enforce and increase the systemic inflammatory response. IL-1 $\beta$ also works in conjunction with $\mathrm{TNF} \alpha$ to increase blood-brain barrier (BBB) permeability. One report documented an association 
between serum IL-1 $\beta$ levels and risk of mortality [8]. Other studies have reported an association between high levels of IL-6 and risk of adverse outcomes in sepsis [9-11]. Randomized clinical trials (RCTs) using biologics to target the cyto/chemokine cascade during sepsis are summarized in the following sections.

\subsection{Anti-Interleukin Therapy}

Interleukin-1 receptor antagonist (IL-1ra) is an endogenous protein produced by immune cells which antagonizes IL-1 mediated responses by competitive inhibition of IL-1 receptors [12,13]. In a pilot study, investigators used human recombinant IL-1ra (hrIL-1ra) in an open-label, placebo-controlled, phase II multicenter trial, to treat sepsis syndrome/shock in 99 patients [14]. A dose-dependent, 28 -day survival benefit was associated with hrIL-1ra treatment $(p=0.015)$. Additionally, dose-related survival benefits were observed with infusion of hrIL-1ra in patients with septic shock $(p=0.002)$, Gram-negative infection $(p=0.04)$, and high circulating IL-6 $(>100 \mathrm{pg} / \mathrm{mL})(p=0.009)$. In a follow-on study with a much larger cohort, hrIL-1ra treatment did not show significant increases in survival overall, but secondary analyses showed that hrIL-1ra treatment was associated with increased survival time among patients with MODS [15].

In a subsequent randomized, double-blind, placebo-controlled trial, investigators tested the efficacy and safety of hrIL-1ra in the treatment of severe sepsis [16]. Patients $(n=696)$ were randomized to receive standard supportive care and antimicrobial therapy in addition to hrIL-1ra (100 mg) or placebo by IV bolus, followed by a 72-h continuous infusion of hrIL-1ra $(2.0 \mathrm{mg} / \mathrm{kg} / \mathrm{h})$ or placebo. However, the study was terminated after interim analysis found it unlikely that the primary efficacy endpoints would be met. The 28-day all-cause mortality rate was statistically insignificant between treatment groups $(p=0.36)$. Additionally, the mortality rate did not significantly differ between groups when analyzed based on infection site, infecting microbe, presence of bacteremia, shock, organ dysfunction, or predicted mortality risk at the beginning of the study. Therefore, the authors concluded that a 72-h continuous IV infusion of hrIL-1ra failed to demonstrate a statistically significant reduction in mortality versus standard therapy.

\subsection{Anti-TNF $\alpha$ Therapy}

Tumor necrosis factor alpha (TNF $\alpha)$ is an inflammatory cytokine produced by all cell types but principally is synthesized and released by macrophages and other immune cells in response to infection and noxious stimuli. Many biologics currently on the market treat chronic inflammatory diseases, such as rheumatoid arthritis, by blocking TNF $\alpha$ with targeted antibodies. In sepsis, high levels of proinflammatory cytokines, particularly TNF $\alpha$ have been thought to increase endothelial cell permeability, which can hinder cells from obtaining necessary nutrients [17]. Additionally, the cell's glycocalyx, the pericellular matrix that surrounds epithelial cell membranes, is susceptible to damage from cytokines, oxidants, and endotoxins [18], further increasing blood-brain-barrier (BBB) permeability [19]. Other deleterious effects of circulating TNF $\alpha$ include myocardial suppression [20-22], cellular glutathione depletion [23] and prostaglandin activation [24,25], all of which contribute to MODS.

Nearly 60 trials were conducted to test the efficacy of anti-TNF $\alpha$ antibodies and IL-1 receptor antagonists before the turn of the 21st century. A meta-analysis of the pooled data from these trials yields a small but statistically significant reduction in 28-day all-cause mortality [26]. However, the minor benefits displayed by these treatments were overshadowed by several factors, including variability in trial results, evidence of the potential for harm, and the high financial costs of these agents. Many of these trials suffered from poor design and included patients who would and would not benefit from experimental treatment, thereby confounding the outcome. Never-the-less, enough promise was shown in these early trials to justify additional studies with improved, 'next-generation' antibody-based therapies targeting cyto/chemokines. These newer therapies were polyclonal antibody fragments (Fabs), primarily comprised of the variable domain (i.e., light chain), with the rationale 
being that their smaller size allowed for increased diffusion into extravascular spaces, and a more permissive binding of TNF $\alpha$.

MONARCS was a phase III RCT performed on over 2500 patients with severe sepsis at 157 centers using the anti-TNF $\alpha$ antibody fragment, afelimomab [27]. This remains one of the largest RCTs ever performed in this patient population. Based on the findings of smaller previous trials using afelimomab [28,29], investigators elected to stratify the initiation of treatment according to patients' serum IL-6 status. Patients designated as 'high IL-6' ( $\geq 1000$ pg/mL) or 'low IL-6' $(<1000$ pg/mL) were randomly assigned to receive afelimomab or placebo for 3 days and then followed for 28 days. Another factor that differentiated this trial from others was that afelimomab was administered via intermittent IV infusions over $72 \mathrm{~h}$, whereas most other trials only gave a study drug once. A small but statistically significant reduction in 28-day all-cause mortality and organ dysfunction was observed with treatment but only in the 'high IL-6' group. Significant decreases in TNF and IL-6 concentrations as well as significant absolute reductions in MODS and SOFA scores were observed vs. placebo in the 'high IL-6' group. A high degree of heterogeneity in the inflammatory status of the patients enrolled in the study at baseline was thought, at least in part, to underlie some of the variability in response to therapy. Authors stated they need a more complex statistical model to detect a treatment effect due to the imbalance of inflammatory status in patients at baseline (IL-6 and TNF levels). Like other trials, treatment in MONARCS was initiated within $24 \mathrm{~h}$ of a patient meeting inclusion criteria. However, current sepsis treatment guidelines recommend initiating therapy within $3 \mathrm{~h}$ of symptom presentation. Thus, additional RCTs with afelimomab where newer guidelines are followed as part of the inclusion criteria may be warranted.

More recently, a double-blind, placebo-controlled, phase IIa trial tested the safety and tolerability of AZD9773, a polyclonal anti-TNF $\alpha$ Fab in patients with severe sepsis [30]. Patients were randomized to receive AZD9773 (including five escalating-dose cohorts) or placebo. For most patients in the AZD9773 cohorts, serum TNF $\alpha$ levels decreased to near-undetectable levels within two hours of administration. In particular, the higher-dose cohorts demonstrated significant lower AUC concentrations of TNF $\alpha$ vs. placebo over the treatment period. This study arguably supports continued evaluation of AZD9773 in larger trials in order to determine whether it yields a clinical benefit. However, the small number of patients enrolled $(n=70)$ and variable baseline TNF $\alpha$ and IL- 6 levels were again a confounding factor. A subsequent randomized, double-blind, placebo-controlled phase IIb trial tested the safety and efficacy of two doses of AZD9773 in patients with severe sepsis/septic shock [31]. In this trial, 300 patients were randomized to receive AZD9773 or placebo for five days. There were no significant differences among treatment groups or subgroups stratified by baseline TNF $\alpha$ level, Acute Physiology, Age, Chronic Health Evaluation (APACHE-II) score at screening, infection site, etc., with respect to number of ventilator-free days, mortality rates, or relative risk of death. The authors even noted that these results do not provide justification to further study AZD9773, though certain subgroups, including the low-dose AZD9773 group baseline APACHE II score 21-C25 and >31, did trend toward significance. Despite the ability of AZD9773 to rapidly decrease TNF $\alpha$ levels (reproducing the phase IIa results), this failed to translate to a clinical benefit. However, given the highly variable baseline inflammatory status among sepsis patients, as highlighted from work in the previous trials, it is likely that this trial $(n=300)$ was insufficiently powered to detect a statistically significant difference in clinical parameters.

\section{Targeting the Innate Immune Response}

\subsection{Alkaline Phosphatase}

Alkaline phosphatase (AP) is a ubiquitous protein that has four main isoenzymes with various roles [32]. It has been shown in animal studies that exogenous intestinal AP (IAP) decreases systemic inflammation, particularly detoxification of bacterial lipopolysaccharides (LPS). A study from Malo et al. [33] showed that circulating TNF $\alpha$ and IL-1 $\beta$ inhibit expression of IAP from intestinal 
endothelial cells, which suggests further susceptibility to bacterial LPS in septic patients due to lack of IAP. A phase II double-blind placebo-controlled clinical trial evaluated whether bovine intestinal alkaline phosphatase (BIAP) improved renal function in 36 patients with severe sepsis or septic shock [34]. A significant improvement of creatinine clearance was observed in the BIAP-treatment group within $24 \mathrm{~h}$, while the placebo group saw a decline of creatinine clearance. Similarly, the BIAP group had significant improvement in average serum creatinine from $1.03 \mathrm{mg} / \mathrm{dL}$ to $0.79 \mathrm{mg} / \mathrm{dL} 7$ days after treatment, while placebo group did not show significant improvement at 7 days. Furthermore, this study excluded patients with chronic renal failure on dialysis, while also providing little data on included patients who received renal replacement therapy (RRT). This makes it difficult to extrapolate renal improvement in more severe populations. Although this study showed promise for BIAP to improve renal function in sepsis, the small patient sample size and limited clinical outcome data ultimately weakened the overall impact of the study. However, with a proper study design, it may be possible to discern a small but significant beneficial effect of BIAP in sepsis patients.

\subsection{Granulocyte-Macrophage Colony Stimulating Factor}

Granulocyte-macrophage colony stimulating factor (GM-CSF) is a growth factor that stimulates the immune system by enhancing the host's cell-killing abilities, principally through activation of neutrophils, macrophages, and monocytes. A preliminary study by Nierhaus et al found that human recombinant GM-CSF upregulated expression of the cell surface antigen mHLA-DR in 9 septic patients with MODS [35]. This is important because low expression of mHLA-DR is a feature of septic patients [36]. GM-CSF was further evaluated in a double-blind, placebo-controlled, RCT of 38 patients with severe sepsis, septic shock, or sepsis-associated immunosuppression [37]. Throughout the study, the treatment group had significantly higher levels of neutrophils, CD4 and CD8 T-lymphocytes, and a significant improvement in APACHE-II score. Despite the treatment arm's success in many areas, there were multiple important variables that did not reach statistical significance. These include decreased ventilator time, decreased hospital and ICU stay, 28-day mortality, NK and B-lymphocyte counts, etc. This lack of statistical significance in key outcomes was likely due to limitations in the study design (e.g., small patient sample, heterogeneity in presentation, etc.) Additionally, the control group had a tendency toward higher baseline disease severity scores. Inclusion for this trial was broad but mainly consisted of patients that met sepsis and MODS criteria but were relatively healthy otherwise. Details of comorbidities were sparse, and no further stratification occurred, which makes it difficult to ascertain select groups that may or may not benefit with specific acute or chronic conditions. Of note, patients with autoimmune diseases, recent myocardial infarctions, and CPR were excluded. Collectively the study demonstrated that GM-CSF does have therapeutic potential with sepsis, but evidence is still lacking. Here again, larger trials with proper design and sufficient statistical power to assess an effect are needed.

\subsection{Intravenous Immunoglobulin}

Intravenous immunoglobulin (IVIG) has been used to treat a number of chronic diseases, including neurological and autoimmune conditions, among others [38]. Therapeutic mechanisms of IVIG is complex and not fully understood, but thought to be multifaceted, including enhanced immune cell function and pathogen clearance, decreased production and/or scavenging of proinflammatory cytokines, and more [39].

There have been many RCTs to determine the efficacy of IVIG as an adjunctive sepsis treatment. Despite these efforts, there are mixed results with no clear consensus. A Cochrane meta-analysis conducted by Alejandra et al. reviewed 43 RCTs and concluded that there was insufficient evidence to support the use of IVIG in septic neonates [40]. Though adult mortality was reduced, the authors stated this benefit was not seen in trials with low risk of bias. Laupland et al. found reduced adult mortality but mention a high level of heterogeneity in the trials analyzed [41]. Additional meta-analyses performed in this timeframe found significant reductions in adult mortality with IVIG use in sepsis 
patients [42,43]. Interestingly, the majority of these analyses were published between 2004 and 2007, with the exception of Alejandra et al. in 2013, which had come to different conclusions with comparable data available at the time. More definitively, the SBITS study, a large phase III trial, found no difference in mortality rates between the control and treatment groups [44], which conflicts with many of the meta-analyses and supports the findings of Alejandra et al. Of the studies examined, there were subgroups that consisted primarily of comparisons of polyclonal IVIG, IgM-enriched polyclonal IVIG, and monoclonal IVIG between adults and neonates. Currently, there is not enough robust data to suggest any mortality benefit. Until clinical benefit can be proven further, the consensus will likely remain scattered.

Thus, although there is weak evidence to support the use of IVIG for the treatment of sepsis, the lack of agreement and inconsistent results obtained to date suggest that IVIG may only provide a minimal benefit in a select group of patients.

\section{Targeting the Coagulant Response}

\subsection{Heparin}

Heparin is a commonly used anticoagulant used to treat and prevent thromboembolic events during hypercoagulable states, such as pregnancy, surgery, and myocardial infarctions. During early stages of sepsis, inflammatory mediators interfere and trigger the coagulation cascade, which can lead to organ dysfunction and other complications [45]. Heparin may attenuate coagulation and thereby act to prevent MODS.

The HETRASE trial was a phase III double-blind, placebo-controlled trial, which aimed to determine if a low-dose continuous infusion of unfractionated heparin (UFH) is an effective complementary treatment in septic patients. The effect of UFH on length of hospital stay, change in MODS score from baseline, and 28-day mortality did not reach statistical significance versus placebo [46]. HETRASE included patients broadly presenting with infection confirmed by both inflammation biomarkers and vital signs. Conversely, admission into the hospital $>24 \mathrm{~h}$ prior to the study, chronic renal failure, history of organ transplantation, and several others were cause for exclusion. As heparin is safe in renal failure, it may have been beneficial in that population. Despite failing to show clinical improvement, heparin was well tolerated. Thus, ubiquity of access and decent safety profile make heparin a good candidate for future studies as an adjunct sepsis treatment.

\subsection{Platelet Activating Factor Acetyl Hydrolase}

Platelet-activating factor (PAF) is an endogenous phospholipid that is produced and released by many cell types in the blood, kidneys, liver, skin and other tissues [47]. When PAF is excreted and binds to PAF-receptors, the effect can be proinflammatory in nature, especially in times of infection with concurrent inflammation, such as sepsis. To counter this effect, the PAF-acetylhydrolase (PAF-AH) enzyme is released into plasma where it hydrolyses PAF and other phospholipids [48], thereby inactivating PAF. The idea that PAF-AH may mitigate inflammation was demonstrated in animal models with recombinant PAF-AH [49], and further elucidated in clinical trials [50].

To date, there has been only a single clinical trial assessing recombinant PAF-AH for severe sepsis. The study was a phase III, double-blind, placebo-controlled trial with 2500 participants from 9 countries, in 146 intensive care units (ICU). Unfortunately, the trial was terminated early due to an interim analysis that determined recombinant PAF-AH (rPAF-AH) had limited clinical benefit in the treatment group. Subsequently, the 28-day all-cause mortality, ARDS incidence, ICU-free days, and degree of MODS did not reach statistical significance [51]. Considering the early phase successes and high tolerability, it may be worthwhile to investigate rPAF-AH further as an adjunct agent for sepsis, but for now, it remains a theoretical option. 


\subsection{Activated Protein C}

Protein $\mathrm{C}$ is a prothrombin and key anticoagulant factor responsible for maintaining hemostasis and vascular permeability $[52,53]$. Recombinant human activated protein C (rhAPC) showed compelling dose-dependent reductions in coagulation and lethality in pre-clinical studies of primates with severe sepsis [54]. Based on the success of the early trials, several large RCTs sought to investigate the safety and efficacy of rhAPC in sepsis.

In 2001, the Food and Drug Administration (FDA) approved drotrecogin alfa (rhAPC, Xigris $®$ ) for adults with severe sepsis at high risk of death. The FDA, however, also required a study to evaluate the efficacy of drotrecogin alfa for adults with severe sepsis at low risk of death. The ADDRESS trial was a double-blind, placebo-controlled multi-center study that randomized patients to receive drotrecogin alfa or placebo [55]. Unfortunately, trial enrollment was terminated due to a low likelihood of meeting the objective of demonstrating a significant reduction in 28-day all-cause mortality in the treatment group. There were no statistically significant differences in 28-day mortality or in-hospital mortality, even when the patients were stratified by APACHE II score, single vs. multiple organ dysfunction, and use of heparin at baseline. Though a subgroup of patients who were the first enrolled showed significantly higher mortality when treated with drotrecogin alfa vs. placebo. Additionally, the rate of serious bleeding was higher with drotrecogin alfa vs. placebo during the infusion and 28-day study periods. Post hoc analyses of the subgroup of patients who had undergone surgery within 30 days before enrollment with concomitant single-organ dysfunction had significantly higher mortality rates with drotrecogin alfa vs. placebo, which was attributed to sepsis. There were also significantly more bleeding events vs. placebo both during infusion and the 28-day study period. Among those surgical patients who had a bleeding event, more patients in the drotrecogin alfa group died of sepsis-induced multi-organ dysfunction or hemorrhage. The authors concluded that drotrecogin alfa should not be used in patients with severe sepsis at low risk for death (single-organ failure or APACHE II score $<25$ ). The number of patients with APACHE II scores $>25$ was too small to detect a significant mortality effect vs. placebo.

Severe sepsis in pediatric patients is poorly understood compared to severe sepsis in adults. The RESOLVE trial was a randomized, double-blind, placebo-controlled phase III trial that investigated biomarker changes in inflammation and coagulation in pediatrics [56]. Pediatric patients with sepsis-induced cardiovascular and respiratory dysfunction were randomized to receive either drotrecogin alfa or placebo. A significant reduction in D-dimer and thrombin-antithrombin complex was observed in the treatment group compared with placebo. However, a median protein $\mathrm{C}$ difference was not observed in the overall treatment population compared with placebo, despite there being a mortality benefit with drotrecogin alfa treatment. In patients $>1$ year of age, the median percentage change from baseline in protein $C$ was significantly higher with dotrecogin alfa vs. placebo. This difference was not observed in patients $<1$ year. When stratifying patients with disseminated intravascular coagulation (DIC) by age group, the median percentage change from baseline in protein $\mathrm{C}$ activity over time did not differ. However, the authors note that changes in protein $C$ trended toward significant increase in children $>1$ year of age. In patients without DIC, the change in protein C over time did not differ among age groups. A notable finding from this study was that children displayed a similar response to therapy as adults in the following key areas, (1) severity of coagulation/inflammation and mortality; and (2) pharmacodynamic response to drotrecogin alfa with respect to protein $\mathrm{C}$ activity and systemic inflammation.

The ENHANCE group sought to provide further evidence for the safety and efficacy of drotrecogin alfa in severe sepsis [57]. In this single-arm, open-label trial, adults with known/suspected infection, 3-4 SIRS criteria, or at least one sepsis-induced organ dysfunction received i.v. infusion of drotrecogin alfa. Treatment was associated with statistically significant relative and absolute risk reductions (RRR and ARR, respectively) in mortality but a statistically insignificant increased risk for bleeding, notably intracranial hemorrhage. It is important to note that placebo patient mortality was less than or equal to drotrecogin alfa-treated patients when stratified by APACHE II score. Another interesting observation 
here was that ENHANCE patients treated within $24 \mathrm{~h}$ from their first sepsis-induced organ dysfunction had lower mortality vs. those treated after $24 \mathrm{~h}$ for all measures of disease severity, except mechanical ventilation and organ dysfunction. Mortality was also numerically higher in all subgroups (when compared to the drotrecogin alfa groups in PROWESS), except for those having $\geq 4$ organs in failure. Additionally, patients $\geq 65$ years of age had significantly higher mortality rates when treated later. Though there is no placebo arm, this study provided supportive evidence for a favorable benefit/risk ratio with rhAPC, and that treatment can be more effective if used sooner.

A prospective, observational, controlled trial tested the efficacy of drotrecogin alfa in the "evolution and outcome" of acute kidney injury (AKI), which complicates acute sepsis-induced cardiopulmonary failure [58]. The authors defined AKI as a persistent oligo-anuria following adequate fluid resuscitation. The most glaring weakness is likely the size of this study, which enrolled only 46 patients. Another major weakness is the lack of blinding since the decision whether to start drotrecogin alfa was left to the discretion of the ICU physician. Oligo-anuria and 28-day mortality were comparable between treatment groups. Baseline characteristics were statistically similar between groups, but this study is far too small to conduct subgroup analyses or conclude that rhAPC is ineffective in treating sepsis-related AKI.

The PROWESS study was a randomized, double-blind, placebo-controlled phase III trial that investigated whether infusion of drotrecogin alfa reduced 28-day all-cause mortality [59]. Patients were randomized to receive either drotrecogin alfa or placebo. Treatment was associated with statistically significant relative and absolute risk reductions (RRR and ARR, respectively) in death but a statistically insignificant increased risk for bleeding. Similar results were found when the groups were stratified by baseline APACHE II score, age, and protein C activity (including the 38 patients who underwent randomization but never received an infusion). Additionally, all subgroup analyses (stratified by APACHE II score, number of dysfunctional organs/systems, sex, age, site of infection, type of infection, and presence/absence of protein $C$ deficiency) yielded similar treatment effects with Xigris $₫ v$ v. placebo. However, the lack of confirmatory data from other placebo-controlled trials called the results of this trial into question. PROWESS-SHOCK enrolled patients with infection, systemic inflammation, and shock in a randomized, double-blind, placebo-controlled trial to receive drotrecogin alfa or placebo [60]. Drotrecogin alfa did not significantly reduce all-cause mortality at 28 or 90 days versus placebo. This includes all subgroups (recent surgery, number of baseline organ failures, etc.). As a result of these findings, the FDA officially withdrew drotrecogin alfa from the market in October 2011, since no statistically significant decrease in 28-day all-cause mortality was found with treatment in the PROWESS-SHOCK trial.

Alterations in protein C levels appear to correlate with sepsis severity. Therefore, the authors of the RESPOND trial hypothesized that it would be possible to tailor therapy with the use of APC [61]. They also wanted a follow-up to the PROWESS trial that responded to patients' protein C levels and modified therapy accordingly. This phase II, randomized, double-blind study determined the dose and duration of drotrecogin alfa by measuring protein $C$ levels vs. standard therapy in patients with severe sepsis. Protein C-deficient patients were randomized to standard therapy (drotrecogin alfa $24 \mathrm{mcg} / \mathrm{kg} / \mathrm{h}$ for $96 \mathrm{~h}$ ) or alternative therapy (drotrecogin alfa at a higher dose and/or variable duration, $24 / 30 / 36 \mathrm{mcg} / \mathrm{kg} / \mathrm{h}$ for $48-168 \mathrm{~h}$ ). There was a statistically significant difference in absolute change in protein $C$ from days $1-7$ between treatment groups. When patients were stratified by protein $C$ deficiency (moderate vs. severe), alternative treatment demonstrated greater protein $C$ increases (though this was only statistically significant for the moderate protein $C$ deficiency group). Among the moderate deficiency population, shorter infusions $(<97 \mathrm{~h})$ resulted in greater mortality. Additionally, higher doses and longer infusions were associated with greater increases in protein $\mathrm{C}$ levels with no serious bleeds. The authors concluded that this study successfully proved variable doses and/or durations of drotrecogin alfa can improve protein $C$ levels, a finding which can be incorporated into future studies. However, this trial did not evaluate the efficacy of rhAPC on mortality or other clinical variables, unlike PROWESS and PROWESS-SHOCK. Moreover, the stratification of patients by level of protein $\mathrm{C}$ deficiency was done at $24 \mathrm{~h}$ rather than baseline, delaying some patients 
from receiving higher doses, resulting in an imbalance between the severe deficiency alternative and standard therapy subgroups.

\section{Conclusions/Perspectives}

There are several broad consensus findings from these trials that, from our perspective, can be informative to both investigators and clinicians alike. First, it is clear that in all biologic-related RCTs performed to date, administration of recombinant proteins appears to be well-tolerated by the septic patient, even in those experiencing septic shock. When considering that these are critically ill patients, it is somewhat surprising that infusion of a recombinant protein has not been associated with worse outcomes. This is encouraging from a feasibility and safety standpoint. Second, despite the failure of many RCTs in this space, there is more than a little evidence at this point that anti-inflammatory therapies can indeed be beneficial, particularly in select patient populations. Specifically, the complete story for anti-IL- 1 and TNF $\alpha$ therapies remains unwritten. In some instances, alterations in study design, even slight alterations, may have led to substantial differences in outcomes. Difficulties in defining proper inclusion/exclusion criteria, and the practical challenges associated with enrolling patients with sepsis remain major obstacles to the field. As observed in the MONARCS trial, it is likely that patients who are still in the 'pro-inflammatory stage' of early sepsis could benefit from anti-TNF $\alpha$ treatment. Indeed, it would seem that several of these anti-cytokine therapy RCTs would have benefited from more stringent biomarker-guiding. While IL-6 was used in the baseline stratification criteria for several trials, the rationale for using only this cytokine, rather than multiple cytokines (including the very targets of the therapies themselves) or serum metabolites is not at all clear. Use of serum metabolites such as lactate $[62,63]$ as biomarkers for inclusion in sepsis RCT's is not routinely employed and yet might be an important variable and offer certain advantages over cytokine measurements. Determination of inflammatory status in a patient can take several hours or longer, due to the time constraints associated with measuring serum cytokines. Given that the newest clinical guidelines for sepsis therapy call for initiation of treatment within the first $3 \mathrm{~h}$ of presentation [1,2], this does not seem compatible with contemporary cytokine detection methods (e.g., enzyme-linked immunosorbent assays, ELISAs). Thus, until newer technologies and/or alternative biomarkers emerge, identifying patients who may benefit the most from treatment remains an elusive goal.

Lastly, it is important to recognize the improvements in guidelines for early management of patients with sepsis and septic shock, the product of the "Surviving Sepsis Campaign [2]." These guidelines primarily focus on implementation of broad-spectrum antibiotics, fluid resuscitation, vasodilators, anticoagulation, and other supportive measures, all of which are evidence-based recommendations. This evidence suggests, perhaps, that a major factor in the effective treatment of sepsis/septic shock may not be hidden behind a novel drug target but rather be dependent on controllable factors such as time for pathogen identification, time to initial antimicrobial medication, and recognition of MODS. Unfortunately, not all institutions possess the same instrumentation and expertise, pharmaceutical formularies, type/amount of drugs, equipment, or staffing, which places limitations on what is achievable. Nevertheless, incorporating these new guidelines into the design and implementation of future RCTs in sepsis/septic shock should improve the clarity of outcomes and hopefully lead to beneficial effects on MODS and mortality in this patient population. 
Table 1. Outcomes and Status of RCT's using Biologics in Sepsis.

\begin{tabular}{cccc}
\hline Biologic Class & Equivocal Outcomes & Beneficial Outcomes & Current Status/Considerations \\
\hline rhAPC & {$[55,56,58,60,64]$} & {$[57,59,61]$} & No clear benefit, discontinued \\
\hline Heparins & {$[46,65]$} & & $\begin{array}{c}\text { Potential for LMWH, not UFH } \\
\text { Potential MODS benefit. } \\
\text { hrIL-1a }\end{array}$ \\
\hline Alk Phos & {$[14-16]$} & $\begin{array}{c}\text { Moed more data in larger trials. } \\
\text { stringent biomarker-guided I/E criteria. }\end{array}$ \\
\hline anti-TNF $\alpha$ & {$[34]$} & {$[27,30]$} & $\begin{array}{c}\text { Need more data in larger trials. } \\
\text { Potential benefit with Fabs. }\end{array}$ \\
\hline IVIG & {$[31]$} & & More stringent biomarker-guided I/E criteria. \\
\hline GM-CSF & {$[44]$} & {$[35,37]$} & No clear benefit. \\
\hline rPAF-AH & & & $\begin{array}{c}\text { Inconclusive. } \\
\text { Need more data in larger trials. }\end{array}$ \\
\hline
\end{tabular}

Author Contributions: All authors contributed equally to the formulation of the concept for this review and in writing/revising the manuscript.

Funding: Funding for this work was provided by National Institutes of Health grants (R01HL122863 and R21AG057006), and Department of Defense grant (PR181276) to E.J.A.

Conflicts of Interest: The authors have no conflicts of interest to disclose.

\section{Abbreviations}

$\begin{array}{ll}\text { MODS } & \text { Multiple organ dysfunction syndrome } \\ \text { SIRS } & \text { Systemic inflammatory response syndrome } \\ \text { TLR } & \text { Toll-like receptor } \\ \text { IL } & \text { Interleukin } \\ \text { TNF } & \text { Tumor necrosis factor } \\ \text { Fab } & \text { Polyclonal antibody fragment } \\ \text { AP } & \text { Alkaline phosphatase } \\ \text { BIAP } & \text { Bovine intestinal alkaline phosphatase } \\ \text { GM-CSF } & \text { Granulocyte-macrophage colony stimulating factor } \\ \text { APACHE } & \text { Acute Physiology, Age, Chronic Health Evaluation } \\ \text { IVIG } & \text { Intravenous immunoglobulin } \\ \text { UFH } & \text { Unfractionated heparin } \\ \text { PAF } & \text { Platelet-activating factor } \\ \text { rhAPC } & \text { Recombinant human activated protein C } \\ \text { RRR } & \text { Relative risk reduction } \\ \text { ARR } & \text { Absolute risk reduction } \\ \text { RCT } & \text { Randomized clinical trial }\end{array}$

\section{References}

1. Singer, M.; Deutschman, C.S.; Seymour, C.W.; Shankar-Hari, M.; Annane, D.; Bauer, M.; Bellomo, R.; Bernard, G.R.; Chiche, J.D.; Coopersmith, C.M.; et al. The Third International Consensus Definitions for Sepsis and Septic Shock (Sepsis-3). JAMA 2016, 315, 801-810. [CrossRef] [PubMed]

2. Rhodes, A.; Evans, L.E.; Alhazzani, W.; Levy, M.M.; Antonelli, M.; Ferrer, R.; Kumar, A.; Sevransky, J.E.; Sprung, C.L.; Nunnally, M.E.; et al. Surviving Sepsis Campaign: International Guidelines for Management of Sepsis and Septic Shock: 2016. Intensive Care Med. 2017, 43, 304-377. [CrossRef] [PubMed]

3. Balk, R.A. Systemic inflammatory response syndrome (SIRS): Where did it come from and is it still relevant today? Virulence 2014, 5, 20-26. [CrossRef] [PubMed] 
4. Lagu, T.; Rothberg, M.B.; Shieh, M.S.; Pekow, P.S.; Steingrub, J.S.; Lindenauer, P.K. Hospitalizations, costs, and outcomes of severe sepsis in the United States 2003 to 2007. Crit. Care Med. 2012, 40, 754-761. [CrossRef] [PubMed]

5. Angus, D.C.; Linde-Zwirble, W.T.; Lidicker, J.; Clermont, G.; Carcillo, J.; Pinsky, M.R. Epidemiology of severe sepsis in the United States: Analysis of incidence, outcome, and associated costs of care. Crit. Care Med. 2001, 29, 1303-1310. [CrossRef] [PubMed]

6. Kumar, G.; Kumar, N.; Taneja, A.; Kaleekal, T.; Tarima, S.; McGinley, E.; Jimenez, E.; Mohan, A.; Khan, R.A.; Whittle, J.; et al. Nationwide trends of severe sepsis in the 21st century (2000-C2007). Chest 2011, 140, 1223-1231. [CrossRef]

7. Chousterman, B.G.; Swirski, F.K.; Weber, G.F. Cytokine storm and sepsis disease pathogenesis. Semin. Immunopathol. 2017, 39, 517-528. [CrossRef]

8. Mera, S.; Tatulescu, D.; Cismaru, C.; Bondor, C.; Slavcovici, A.; Zanc, V.; Carstina, D.; Oltean, M. Multiplex cytokine profiling in patients with sepsis. APMIS 2011, 119, 155-163. [CrossRef]

9. Gouel-Cheron, A.; Allaouchiche, B.; Guignant, C.; Davin, F.; Floccard, B.; Monneret, G.; AzuRea, G. Early interleukin-6 and slope of monocyte human leukocyte antigen-DR: A powerful association to predict the development of sepsis after major trauma. PLOS ONE 2012, 7, e33095. [CrossRef]

10. Wu, H.P.; Chen, C.K.; Chung, K.; Tseng, J.C.; Hua, C.C.; Liu, Y.C.; Chuang, D.Y.; Yang, C.H. Serial cytokine levels in patients with severe sepsis. Inflamm. Res. 2009, 58, 385-393. [CrossRef]

11. Kellum, J.A.; Kong, L.; Fink, M.P.; Weissfeld, L.A.; Yealy, D.M.; Pinsky, M.R.; Fine, J.; Krichevsky, A.; Delude, R.L.; Angus, D.C.; et al. Understanding the inflammatory cytokine response in pneumonia and sepsis: Results of the Genetic and Inflammatory Markers of Sepsis (GenIMS) Study. Arch. Intern. Med. 2007, 167, 1655-1663. [CrossRef] [PubMed]

12. Arend, W.P.; Welgus, H.G.; Thompson, R.C.; Eisenberg, S.P. Biological properties of recombinant human monocyte-derived interleukin 1 receptor antagonist. J. Clin. Investig. 1990, 85, 1694-1697. [CrossRef] [PubMed]

13. Hannum, C.H.; Wilcox, C.J.; Arend, W.P.; Joslin, F.G.; Dripps, D.J.; Heimdal, P.L.; Armes, L.G.; Sommer, A.; Eisenberg, S.P.; Thompson, R.C. Interleukin-1 receptor antagonist activity of a human interleukin-1 inhibitor. Nature 1990, 343, 336-340. [CrossRef] [PubMed]

14. Fisher, C.J., Jr.; Slotman, G.J.; Opal, S.M.; Pribble, J.P.; Bone, R.C.; Emmanuel, G.; Ng, D.; Bloedow, D.C.; Catalano, M.A.; IL-1RA Sepsis Syndrome Study Group. Initial evaluation of human recombinant interleukin-1 receptor antagonist in the treatment of sepsis syndrome: A randomized, open-label, placebo-controlled multicenter trial. Crit. Care Med. 1994, 22, 12-21.

15. Fisher, C.J., Jr.; Dhainaut, J.F.; Opal, S.M.; Pribble, J.P.; Balk, R.A.; Slotman, G.J.; Iberti, T.J.; Rackow, E.C.; Shapiro, M.J.; Greenman, R.L.; et al. Recombinant human interleukin 1 receptor antagonist in the treatment of patients with sepsis syndrome. Results from a randomized, double-blind, placebo-controlled trial. Phase III rhIL-1ra Sepsis Syndrome Study Group. JAMA 1994, 271, 1836-1843. [CrossRef]

16. Opal, S.M.; Fisher, C.J., Jr.; Dhainaut, J.F.; Vincent, J.L.; Brase, R.; Lowry, S.F.; Sadoff, J.C.; Slotman, G.J.; Levy, H.; Balk, R.A.; et al. Confirmatory interleukin-1 receptor antagonist trial in severe sepsis: A phase III, randomized, double-blind, placebo-controlled, multicenter trial. The Interleukin-1 Receptor Antagonist Sepsis Investigator Group. Crit. Care Med. 1997, 25, 1115-1124. [CrossRef]

17. Nooteboom, A.; Van Der Linden, C.J.; Hendriks, T. Tumor necrosis factor-alpha and interleukin-1beta mediate endothelial permeability induced by lipopolysaccharide-stimulated whole blood. Crit. Care Med. 2002, 30, 2063-2068. [CrossRef]

18. Ince, C.; Mayeux, P.R.; Nguyen, T.; Gomez, H.; Kellum, J.A.; Ospina-Tascon, G.A.; Hernandez, G.; Murray, P.; De Backer, D.; Workgroup, A.X. The Endothelium in Sepsis. Shock 2016, 45, 259-270. [CrossRef]

19. Chelazzi, C.; Villa, G.; Mancinelli, P.; De Gaudio, A.R.; Adembri, C. Glycocalyx and sepsis-induced alterations in vascular permeability. Crit. Care. 2015, 19, 26. [CrossRef]

20. Eichenholz, P.W.; Eichacker, P.Q.; Hoffman, W.D.; Banks, S.M.; Parrillo, J.E.; Danner, R.L.; Natanson, C. Tumor necrosis factor challenges in canines: Patterns of cardiovascular dysfunction. Am. J. Physiol. 1992, 263, H668-H675. [CrossRef]

21. Natanson, C.; Eichenholz, P.W.; Danner, R.L.; Eichacker, P.Q.; Hoffman, W.D.; Kuo, G.C.; Banks, S.M.; MacVittie, T.J.; Parrillo, J.E. Endotoxin and tumor necrosis factor challenges in dogs simulate the cardiovascular profile of human septic shock. J. Exp. Med. 1989, 169, 823-832. [CrossRef] [PubMed] 
22. Bozkurt, B.; Kribbs, S.B.; Clubb, F.J., Jr.; Michael, L.H.; Didenko, V.V.; Hornsby, P.J.; Seta, Y.; Oral, H.; Spinale, F.G.; Mann, D.L. Pathophysiologically relevant concentrations of tumor necrosis factor-alpha promote progressive left ventricular dysfunction and remodeling in rats. Circulation 1998, 97, 1382-1391. [CrossRef]

23. Liu, B.; Andrieu-Abadie, N.; Levade, T.; Zhang, P.; Obeid, L.M.; Hannun, Y.A. Glutathione regulation of neutral sphingomyelinase in tumor necrosis factor-alpha-induced cell death. J. Biol. Chem. 1998, 273, 11313-11320. [CrossRef] [PubMed]

24. Jayadev, S.; Linardic, C.M.; Hannun, Y.A. Identification of arachidonic acid as a mediator of sphingomyelin hydrolysis in response to tumor necrosis factor alpha. J. Biol. Chem. 1994, 269, 5757-5763. [PubMed]

25. Liu, S.J.; McHowat, J. Stimulation of different phospholipase A2 isoforms by TNF-alpha and IL-1beta in adult rat ventricular myocytes. Am. J. Physiol. 1998, 275, H1462-H1472.

26. Marshall, J.C. Clinical trials of mediator-directed therapy in sepsis: What have we learned? Intensive Care Med. 2000, 26 (Suppl. 1), S75-S83. [CrossRef]

27. Panacek, E.A.; Marshall, J.C.; Albertson, T.E.; Johnson, D.H.; Johnson, S.; MacArthur, R.D.; Miller, M.; Barchuk, W.T.; Fischkoff, S.; Kaul, M.; et al. Efficacy and safety of the monoclonal anti-tumor necrosis factor antibody $\mathrm{F}\left(\mathrm{ab}^{\prime}\right) 2$ fragment afelimomab in patients with severe sepsis and elevated interleukin-6 levels. Crit. Care Med. 2004, 32, 2173-2182. [CrossRef]

28. Reinhart, K.; Wiegand-Lohnert, C.; Grimminger, F.; Kaul, M.; Withington, S.; Treacher, D.; Eckart, J.; Willatts, S.; Bouza, C.; Krausch, D.; et al. Assessment of the safety and efficacy of the monoclonal anti-tumor necrosis factor antibody-fragment, MAK 195F, in patients with sepsis and septic shock: A multicenter, randomized, placebo-controlled, dose-ranging study. Crit. Care Med. 1996, 24, 733-742. [CrossRef]

29. Gallagher, J.; Fisher, C.; Sherman, B.; Munger, M.; Meyers, B.; Ellison, T.; Fischkoff, S.; Barchuk, W.T.; Teoh, L.; Velagapudi, R. A multicenter, open-label, prospective, randomized, dose-ranging pharmacokinetic study of the anti-TNF-alpha antibody afelimomab in patients with sepsis syndrome. Intensive Care Med. 2001, 27, 1169-1178. [CrossRef]

30. Morris, P.E.; Zeno, B.; Bernard, A.C.; Huang, X.; Das, S.; Edeki, T.; Simonson, S.G.; Bernard, G.R. A placebo-controlled, double-blind, dose-escalation study to assess the safety, tolerability and pharmacokinetics/pharmacodynamics of single and multiple intravenous infusions of AZD9773 in patients with severe sepsis and septic shock. Crit. Care 2012, 16, R31. [CrossRef]

31. Bernard, G.R.; Francois, B.; Mira, J.P.; Vincent, J.L.; Dellinger, R.P.; Russell, J.A.; Larosa, S.P.; Laterre, P.F.; Levy, M.M.; Dankner, W.; et al. Evaluating the efficacy and safety of two doses of the polyclonal anti-tumor necrosis factor-alpha fragment antibody AZD9773 in adult patients with severe sepsis and/or septic shock: Randomized, double-blind, placebo-controlled phase IIb study*. Crit. Care Med. 2014, 42, 504-511. [CrossRef] [PubMed]

32. Sharma, U.; Pal, D.; Prasad, R. Alkaline phosphatase: An overview. Indian J. Clin. Biochem. 2014, 29, $269-278$. [CrossRef] [PubMed]

33. Malo, M.S.; Biswas, S.; Abedrapo, M.A.; Yeh, L.; Chen, A.; Hodin, R.A. The pro-inflammatory cytokines, IL-1beta and TNF-alpha, inhibit intestinal alkaline phosphatase gene expression. DNA Cell Biol. 2006, 25, 684-695. [CrossRef] [PubMed]

34. Heemskerk, S.; Masereeuw, R.; Moesker, O.; Bouw, M.P.; van der Hoeven, J.G.; Peters, W.H.; Russel, F.G.; Pickkers, P.; Group, A.S. Alkaline phosphatase treatment improves renal function in severe sepsis or septic shock patients. Crit. Care Med. 2009, 37, 417-423.e1. [CrossRef]

35. Nierhaus, A.; Montag, B.; Timmler, N.; Frings, D.P.; Gutensohn, K.; Jung, R.; Schneider, C.G.; Pothmann, W.; Brassel, A.K.; Schulte Am Esch, J. Reversal of immunoparalysis by recombinant human granulocyte-macrophage colony-stimulating factor in patients with severe sepsis. Intensive Care Med. 2003, 29, 646-651. [CrossRef]

36. Wu, J.F.; Ma, J.; Chen, J.; Ou-Yang, B.; Chen, M.Y.; Li, L.F.; Liu, Y.J.; Lin, A.H.; Guan, X.D. Changes of monocyte human leukocyte antigen-DR expression as a reliable predictor of mortality in severe sepsis. Crit. Care 2011, 15, R220. [CrossRef]

37. Meisel, C.; Schefold, J.C.; Pschowski, R.; Baumann, T.; Hetzger, K.; Gregor, J.; Weber-Carstens, S.; Hasper, D.; Keh, D.; Zuckermann, H.; et al. Granulocyte-macrophage colony-stimulating factor to reverse sepsis-associated immunosuppression: A double-blind, randomized, placebo-controlled multicenter trial. Am. J. Respir. Crit. Care Med. 2009, 180, 640-648. [CrossRef] 
38. Jolles, S.; Sewell, W.A.; Misbah, S.A. Clinical uses of intravenous immunoglobulin. Clin. Exp. Immunol 2005, 142, 1-11. [CrossRef]

39. Shankar-Hari, M.; Spencer, J.; Sewell, W.A.; Rowan, K.M.; Singer, M. Bench-to-bedside review: Immunoglobulin therapy for sepsis - biological plausibility from a critical care perspective. Crit. Care 2012, 16, 206. [CrossRef]

40. Alejandria, M.M.; Lansang, M.A.; Dans, L.F.; Mantaring, J.B., 3rd. Intravenous immunoglobulin for treating sepsis, severe sepsis and septic shock. Cochrane Database Syst Rev. 2013. [CrossRef]

41. Laupland, K.B.; Kirkpatrick, A.W.; Delaney, A. Polyclonal intravenous immunoglobulin for the treatment of severe sepsis and septic shock in critically ill adults: A systematic review and meta-analysis. Crit. Care Med. 2007, 35, 2686-2692. [PubMed]

42. Kreymann, K.G.; de Heer, G.; Nierhaus, A.; Kluge, S. Use of polyclonal immunoglobulins as adjunctive therapy for sepsis or septic shock. Crit. Care Med. 2007, 35, 2677-2685. [PubMed]

43. Capasso, L.; Borrelli, A.; Cerullo, J.; Pisanti, R.; Figliuolo, C.; Izzo, F.; Paccone, M.; Ferrara, T.; Lama, S.; Raimondi, F. Role of immunoglobulins in neonatal sepsis. Transl Med. UniSa 2015, 11, 28-33. [PubMed]

44. Werdan, K.; Pilz, G.; Bujdoso, O.; Fraunberger, P.; Neeser, G.; Schmieder, R.E.; Viell, B.; Marget, W.; Seewald, M.; Walger, P.; et al. Score-based immunoglobulin G therapy of patients with sepsis: The SBITS study. Crit. Care Med. 2007, 35, 2693-2701.

45. Li, X.; Ma, X. The role of heparin in sepsis: Much more than just an anticoagulant. Br. J. Haematol 2017, 179, 389-398. [CrossRef]

46. Jaimes, F.; De La Rosa, G.; Morales, C.; Fortich, F.; Arango, C.; Aguirre, D.; Munoz, A. Unfractioned heparin for treatment of sepsis: A randomized clinical trial (The HETRASE Study). Crit. Care Med. 2009, 37, 1185-1196. [CrossRef]

47. Palur Ramakrishnan, A.V.; Varghese, T.P.; Vanapalli, S.; Nair, N.K.; Mingate, M.D. Platelet activating factor: A potential biomarker in acute coronary syndrome? Cardiovasc. Ther. 2017, 35, 64-70. [CrossRef]

48. Graham, R.M.; Stephens, C.J.; Silvester, W.; Leong, L.L.; Sturm, M.J.; Taylor, R.R. Plasma degradation of platelet-activating factor in severely ill patients with clinical sepsis. Crit. Care Med. 1994, 22, $204-212$. [CrossRef]

49. Hofbauer, B.; Saluja, A.K.; Bhatia, M.; Frossard, J.L.; Lee, H.S.; Bhagat, L.; Steer, M.L. Effect of recombinant platelet-activating factor acetylhydrolase on two models of experimental acute pancreatitis. Gastroenterology 1998, 115, 1238-1247. [CrossRef]

50. Schuster, D.P.; Metzler, M.; Opal, S.; Lowry, S.; Balk, R.; Abraham, E.; Levy, H.; Slotman, G.; Coyne, E.; Souza, S.; et al. Recombinant platelet-activating factor acetylhydrolase to prevent acute respiratory distress syndrome and mortality in severe sepsis: Phase IIb, multicenter, randomized, placebo-controlled, clinical trial. Crit. Care Med. 2003, 31, 1612-1619. [CrossRef]

51. Opal, S.; Laterre, P.F.; Abraham, E.; Francois, B.; Wittebole, X.; Lowry, S.; Dhainaut, J.F.; Warren, B.; Dugernier, T.; Lopez, A.; et al. Recombinant human platelet-activating factor acetylhydrolase for treatment of severe sepsis: Results of a phase III, multicenter, randomized, double-blind, placebo-controlled, clinical trial. Crit. Care Med. 2004, 32, 332-341. [CrossRef] [PubMed]

52. Bouwens, E.A.; Stavenuiter, F.; Mosnier, L.O. Mechanisms of anticoagulant and cytoprotective actions of the protein C pathway. J. Thromb. Haemost. 2013, 11 (Suppl. 1), 242-253. [CrossRef]

53. Mosnier, L.O.; Zlokovic, B.V.; Griffin, J.H. The cytoprotective protein C pathway. Blood 2007, 109, $3161-3172$. [CrossRef] [PubMed]

54. Taylor, F.B., Jr.; Chang, A.; Esmon, C.T.; D’Angelo, A.; Vigano-D’Angelo, S.; Blick, K.E. Protein C prevents the coagulopathic and lethal effects of Escherichia coli infusion in the baboon. J. Clin. Investig. 1987, 79, 918-925. [CrossRef] [PubMed]

55. Abraham, E.; Laterre, P.F.; Garg, R.; Levy, H.; Talwar, D.; Trzaskoma, B.L.; Francois, B.; Guy, J.S.; Bruckmann, M.; Rea-Neto, A.; et al. Drotrecogin alfa (activated) for adults with severe sepsis and a low risk of death. N. Engl. J. Med. 2005, 353, 1332-1341. [CrossRef]

56. Dalton, H.J.; Carcillo, J.A.; Woodward, D.B.; Short, M.A.; Williams, M.D. Biomarker response to drotrecogin alfa (activated) in children with severe sepsis: Results from the RESOLVE clinical trial ${ }^{*}$. Pediatr. Crit. Care Med. 2012, 13, 639-645. [CrossRef] 
57. Vincent, J.L.; Bernard, G.R.; Beale, R.; Doig, C.; Putensen, C.; Dhainaut, J.F.; Artigas, A.; Fumagalli, R.; Macias, W.; Wright, T.; et al. Drotrecogin alfa (activated) treatment in severe sepsis from the global open-label trial ENHANCE: Further evidence for survival and safety and implications for early treatment. Crit. Care Med. 2005, 33, 2266-2277. [CrossRef]

58. Janssen van Doorn, K.; Spapen, H.; Geers, C.; Diltoer, M.; Shabana, W. Sepsis-related acute kidney injury: A protective effect of drotrecogin alpha (activated) treatment? Acta Anaesthesiol. Scand. 2008, 52, 1259-1264. [CrossRef]

59. Bernard, G.R.; Vincent, J.L.; Laterre, P.F.; LaRosa, S.P.; Dhainaut, J.F.; Lopez-Rodriguez, A.; Steingrub, J.S.; Garber, G.E.; Helterbrand, J.D.; Ely, E.W.; et al. Efficacy and safety of recombinant human activated protein C for severe sepsis. N. Engl. J. Med. 2001, 344, 699-709. [CrossRef]

60. Ranieri, V.M.; Thompson, B.T.; Barie, P.S.; Dhainaut, J.F.; Douglas, I.S.; Finfer, S.; Gardlund, B.; Marshall, J.C.; Rhodes, A.; Artigas, A.; et al. Drotrecogin alfa (activated) in adults with septic shock. N. Engl. J. Med. 2012, 366, 2055-2064. [CrossRef]

61. Shorr, A.F.; Janes, J.M.; Artigas, A.; Tenhunen, J.; Wyncoll, D.L.; Mercier, E.; Francois, B.; Vincent, J.L.; Vangerow, B.; Heiselman, D.; et al. Randomized trial evaluating serial protein C levels in severe sepsis patients treated with variable doses of drotrecogin alfa (activated). Crit. Care 2010, 14, R229. [CrossRef] [PubMed]

62. Nguyen, H.B.; Rivers, E.P.; Knoblich, B.P.; Jacobsen, G.; Muzzin, A.; Ressler, J.A.; Tomlanovich, M.C. Early lactate clearance is associated with improved outcome in severe sepsis and septic shock. Crit. Care Med. 2004, 32, 1637-1642. [CrossRef] [PubMed]

63. Suetrong, B.; Walley, K.R. Lactic Acidosis in Sepsis: It's Not All Anaerobic: Implications for Diagnosis and Management. Chest 2016, 149, 252-261. [CrossRef] [PubMed]

64. Derhaschnig, U.; Reiter, R.; Knobl, P.; Baumgartner, M.; Keen, P.; Jilma, B. Recombinant human activated protein C (rhAPC; drotrecogin alfa [activated]) has minimal effect on markers of coagulation, fibrinolysis, and inflammation in acute human endotoxemia. Blood 2003, 102, 2093-2098. [CrossRef] [PubMed]

65. Levi, M.; Levy, M.; Williams, M.D.; Douglas, I.; Artigas, A.; Antonelli, M.; Wyncoll, D.; Janes, J.; Booth, F.V.; Wang, D.; et al. Prophylactic heparin in patients with severe sepsis treated with drotrecogin alfa (activated). Am. J. Respir. Crit. Care Med. 2007, 176, 483-490. [CrossRef] [PubMed]

(C) 2019 by the authors. Licensee MDPI, Basel, Switzerland. This article is an open access article distributed under the terms and conditions of the Creative Commons Attribution (CC BY) license (http://creativecommons.org/licenses/by/4.0/). 